\title{
SURVEI SITUS PEMBANGUNAN OBSERVATORIUM ASTRONOMI ITERA LAMPUNG DI TAHURA WAR, GUNUNG BETUNG
}

\author{
Robiatul Muztaba ${ }^{1, \text { a) }}$, Annisa Novia Indra Putri ${ }^{1}$, Nindhita Pratiwi ${ }^{1}$, Wahyu \\ Sasongko Putro ${ }^{1}$, Wirid Birastri ${ }^{1}$, Hakim L. Malasan ${ }^{2}$ \\ ${ }^{1}$ Program Studi Sains Atmosfer dan Keplanetan, Observatorium Astronomi Lampung, Institut Teknologi \\ Sumatera, Jalan Terusan Ryacudu, Desa Way Hui, Kecamatan Jati Agung, Kabupaten Lampung Selatan, \\ Lampung 35365. \\ ${ }^{2}$ Program Studi Astronomi, Observatorium Bosscha, Institut Teknologi Bandung, Jl. Tamansari No. 64 \\ Kelurahan Tamansari, Kecamatan Bandung Wetan, Kota Bandung, Jawa Barat 40116.
}

Email: a) $\underline{\text { robiatul.muztaba@aps.itera.ac.id }}$

\begin{abstract}
Abstrak
Pada tahun 2016, Institut Teknologi Sumatera bersama dengan Institut Teknologi Bandung, dan Pemerintah Provinsi Lampung menggagas pembangunan sebuah observatorium baru di Lampung. Kami memaparkan hasil survei astronomi pada akhir tahun 2017 di lokasi observatorium. Adapun tujuan dilakukannya survei astronomi yaitu untuk mengkaji kelayakan sebuah observatorium terhadap kondisi lingkungan dan kualitas langit, serta mendapatkan hasil pengukuran parameter atmosfer meliputi ekstingsi atmosfer, seeing, dan kecerlangan langit. Data hasil survei menjadi bahan pertimbangan dalam pemilihan instrumen dan jadwal rencana pengamatan. Dari hasil penelitian didapat bahwa rata-rata curah hujan minimum terjadi pada bulan Mei sampai Oktober, peta sebaran polusi cahaya dari pengukuran kecerlangan langit menunjukan adanya kontribusi polusi cahaya dari arah timur menuju pusat kota Bandar Lampung. Provinsi Lampung termasuk dalam kategori daerah transisi urban dengan nilai kecerlangan langit sebesar $20.85 \mathrm{mag} \operatorname{arcsec}^{-2}$. Sedangkan untuk pengukuran seeing didapat hasil 1.50 " dan pengukuran ekstingsi menunjukkan grafik dengan kondisi atmosfer yang cukup baik untuk pengamatan.
\end{abstract}

Kata-kata kunci: Survei Astronomi, Parameter Atmosfer, Kecerlangan Langit, Seeing, Ekstingsi.

\begin{abstract}
In 2016, Institut Teknologi Sumatera along with Institut Teknologi Bandung, and the Government of Lampung Province initiated the construction of a new observatory in Lampung. We present the results of astronomical surveys at the end of 2017 at the observatory site. The objective of the survey is to assess the feasibility an astronomical observatory to the environmental conditions and the quality of the sky, as well as to get the atmospheric parameters measurements to include atmospheric extinction, seeing, and sky brightness. The results are taken into account in the selection of instruments and schedules of observation plans. From our research, we get that the average minimum rainfall occurs in May through October, the light pollution distribution maps of the sky brightness measurements showed the presence of light pollution contribution from the east toward downtown Bandar Lampung. Lampung province included in the category of urban transition area with sky brightness value amounted to 20.85 mag arcsec-2. As for the seeing measurement, we get a value of about 1.50 " and the measurement of extinction shows a graph with atmospheric conditions which is good enough for observation.
\end{abstract}

Keywords: Astronomical Survey, Atmospheric Parameter, Sky Brightness, Seeing, Extinction. 


\section{PENDAHULUAN}

Pemerintah Provinsi Lampung bersama Institut Teknologi Sumatera (ITERA) dan Institut Teknologi Bandung (ITB) telah mencanangkan rencana pembangunan Observatorium Astronomi Lampung (OAL) pada tahun 2016 di Taman Hutan Raya Wan Abdur Rahman (TAHURA WAR), Gunung Betung, Kabupaten Pesawaran, Lampung. Titik lokasi observatorium memiliki koordinat geografis $05^{\circ} 27.127^{\prime}$ LS dan $105^{\circ} 09.106^{\prime}$ BT dengan ketinggian 1030 mdpl. Pemerintah Provinsi Lampung telah menghibahkan 30 hektar dari 250 hektar kawasan TAHURA WAR untuk kepentingan pembangunan Observatorium. Keberadaan OAL di Provinsi Lampung merupakan titik baru fasilitas pendidikan dan penelitian dalam jaringan pengamatan astronomi dan astrofisika. Langkah penting dalam studi kelayakan suatu pembangunan observatorium adalah pengukuran parameter atmosfer di bawah lapisan dan kualitas kecerlangan langit di lokasi observatorium (secara in-situ). Dalam merancang suatu program pemasangan instrumen astronomi seperti teleskop, kamera, spektrograf bergantung dengan kondisi lokal meteorologis (microclimate), statistika awan, kualitas langit, objek, dan waktu pengamatan. Studi kelayakan suatu pembangunan observatorium menjadi penting dengan melakukan proses pengukuran parameter atmosfer seperti kondisi meteorologis (temperatur, kelembaban, arah dan kecepatan angin, dan tekanan barometrik), statistika awan (pola awan, curah hujan), seeing, scintillation, turbulensi ekstingsi atmosfer, kecerlangan langit dan polusi cahaya. Hasil dari pengukuran survei astronomi tersebut dapat dijadikan bahan pertimbangan dalam mendesain teleskop, layak atau tidaknya suatu observatorium terhadap pemilihan instrumen, minimal magnitudo linier suatu objek langit yang akan diamati, dan merancang kebutuhan penelitian pada jendela waktu pengamatan yang ideal. Di Bagian 2, membahas rincian survei, termasuk pengaturan perangkat pengukuran dan teknik pengumpulan data. Database yang dihasilkan menjadi data primer dalam mengkaji kelayakan observatorium. Hasil analisis dan diskusi dapat ditemukan di Bagian 3, berfokus pada pembahasan hasil pengamatan dan saran untuk pembangunan observatorium. Kesimpulan dari penelitian ini disajikan dalam Bagian 4.

\section{DATA DAN METODE}

Metodologi survey situs untuk Pembangunan Observatorium Astronomi Lampung (OAL) di Taman Hutan Raya Wan Abdur Rahman (TAHURA WAR), Gunung Betung Lampung ini meliputi empat tahapan utama diantaranya (1) Tahap persiapan atau prepatory, (2) Survey Astronomi dan Meteorologi, dan (3) Pengolahan data dan (4) Tahap analisis yang selanjutnya akan menghasilkan rekomendasi kebutuhan observatorium. Deskripsi alur metodologi dapat dilihat pada GAMBAR 1.

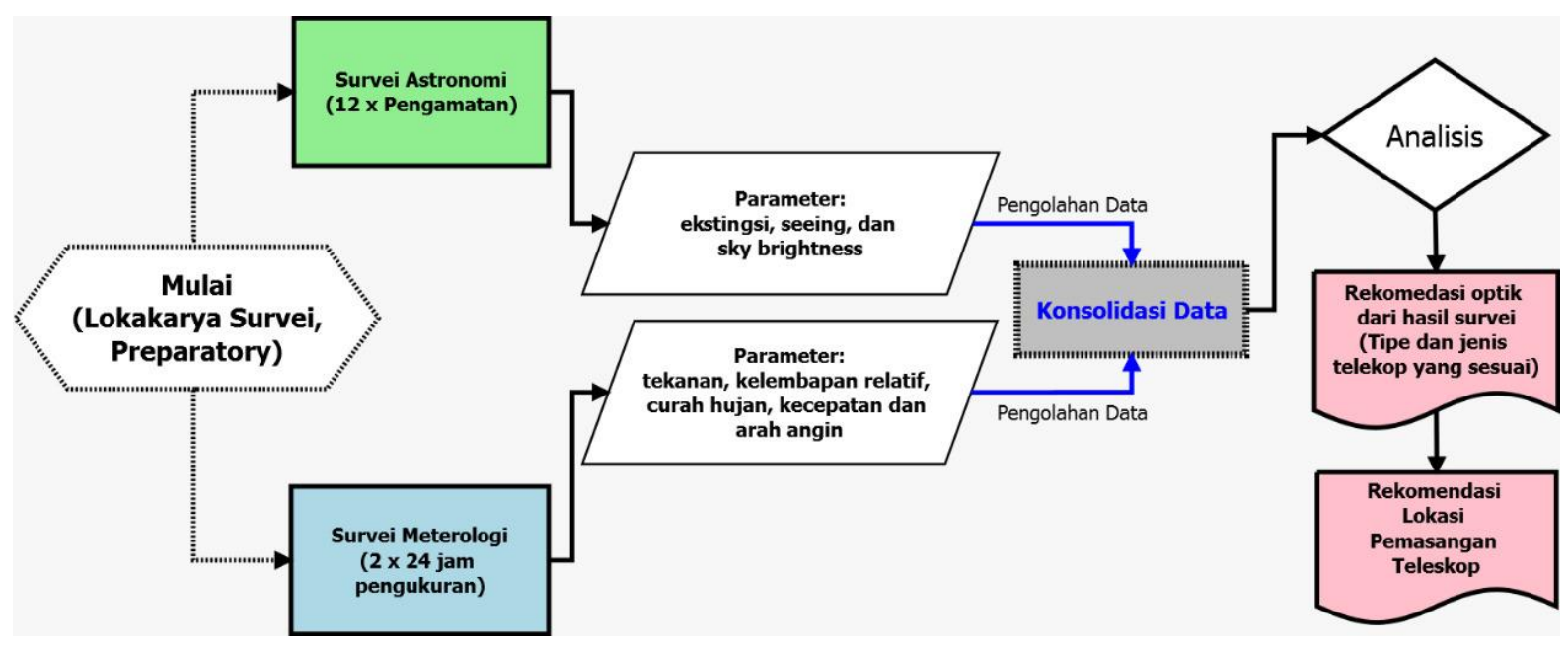

GAMBAR 1. Bagan metodologi survey parameter astronomi dan atmosfer.

Adapun instrumen yang digunakan dalam melakukan kegiatan survei yaitu Teleskop Meade 8" LX90 F/10 yang dipadukan dengan detektor CCD SBIG ST-7XME resolusi $765 \times 510$ piksel dengan 
masing-masing piksel berukuran 9 mikron $\times 9$ mikron, kamera ZWO ASI 178MM resolusi $3096 \times$ 2080 piksel dengan masing-masing piksel berukuran 2,4 mikron, dan Sky Quality Meter (SQM) dengan sistem sensor memiliki panjang gelombang pusat $540 \mathrm{~nm}$ dan Full Widht Half Maximum (FWHM) $240 \mathrm{~nm}$ dengan ketepatan mencapai $\pm 0,10$ mag $\operatorname{arcsec}^{-2}[1,2,3]$. Ketepatan ini konsisten dengan observasi lapangan [4,5]. Pengamatan yang dilakukan dalam kegiatan survei astronomi situs pembangunan observatorium di Gunung Betung meliputi,

\section{Ekstingsi Atmosfer}

Pengamatan dilakukan pada hari Senin tanggal 6 Agustus 2017 mulai dari pukul 19.00 hingga hari Minggu tanggal 7 Agustus 2017 pukul 06.00. Objek bintang diambil dari katalog bintang standar Johnson-Morgan UBVRI. Sistem Johnson-Morgan UBVRI merupakan sistem fotometrik yang paling sering digunakan $[6,7,8]$. Citra bintang yang berhasil diambil pada waktu pengamatan yaitu bintang Arcturus, Cursa, Alnath, dan Muphrid. Parameter awal dari keempat bintang tersebut dapat dilihat pada TABEL 1.

TABEL 1. Parameter awal objek [9].

\begin{tabular}{lcccc}
\cline { 2 - 5 } Parameter & $\begin{array}{c}\text { Arcturus } \\
(\boldsymbol{\alpha} \text { Boo })\end{array}$ & $\begin{array}{c}\text { Cursa } \\
(\boldsymbol{\beta} \text { Eri) }\end{array}$ & $\begin{array}{c}\text { Alnath } \\
(\boldsymbol{\beta} \text { Tau) }\end{array}$ & $\begin{array}{c}\text { Muphrid } \\
(\boldsymbol{\eta} \text { Boo })\end{array}$ \\
\hline RA & $14^{\mathrm{h}} 15^{\mathrm{m}} 38,45^{\mathrm{s}}$ & $05^{\mathrm{h}} 08^{\mathrm{m}} 44,52^{\mathrm{s}}$ & $05^{\mathrm{h}} 27^{\mathrm{m}} 26,30^{\mathrm{s}}$ & $13^{\mathrm{h}} 55^{\mathrm{m}} 32,76^{\mathrm{s}}$ \\
Deklinasi & $19^{\circ} 05^{\prime} 20,6^{\prime \prime}$ & $-05^{\circ} 03^{\prime} 57,7^{\prime \prime}$ & $28^{\mathrm{o}} 37^{\prime} 08,5^{\prime}$ & $18^{\mathrm{o}} 18^{\prime} 33,3^{\prime \prime}$ \\
V & $-0,05$ & 2,79 & 1,65 & 2,68 \\
B-V & 1,23 & 0,13 & $-0,13$ & 0,58 \\
V-R & 0,98 & 0,14 & $-0,01$ & 0,44 \\
V-I & 1,63 & 0,22 & 0,22 & 0,73 \\
\hline
\end{tabular}

Data citra bintang mentah ini kemudian diolah melalui proses reduksi citra (bias, dark, dan flat) menjadi citra bersih menggunakan software IRAF. Citra yang sudah direduksi kemudian ditentukan magnitudo instrumen setiap objek pada filter BVRI dan massa udara.

\section{Seeing}

Teknik dalam pengukuran seeing salah satunya menggunakan citra trail. Adapun objek bintang yang menjadi target yaitu Formalhout dan Albireo. Citra hasil pengamatan dikoreksi dari efek instrumental menggunakan perangkat lunak IRAF (Image Reduction and Analysis Facility) di sistem operasi Unix dan Linux [10,11,12]. Citra mentah yang telah direduksi oleh citra dark kemudian dirotasi beberapa derajat untuk memudahkan menghitung nilai fit dari citra trail. Nilai seeing diukur menggunakan algoritma Gocherman. Sebagai ukuran gerakan pada citra bintang akibat turbulensi atmosfer, didefinisikan sebagai nilai rata-rata akar-kuadrat $\sigma_{\lambda}$ pada panjang gelombang tertentu $\lambda$ dari penyimpangan posisional satu dimensi. Dengan terus-menerus memindahkan citra bintang ke satu arah, katakanlah di x, memungkinkan pemisahan penyimpangan posisi satu dimensi kearah y, maka standar deviasi dapat dituliskan sebagai berikut:

$$
\sigma_{\lambda}=\sqrt{\frac{1}{n-1} \sum_{i=1}^{n}\left(y_{\mathrm{mi}}-\bar{y}_{\mathrm{pi}}\right)^{2}}
$$

untuk mendapatkan pengukuran nilai seeing dalam detik busur. Namun, $\sigma_{\lambda}$ efek seeing disebabkan oleh lapisan turbulensi atmosfer tunggal dengan diameter beberapa sentimeter. Oleh karena itu juga dapat dikaitkan dengan nilai lebar penuh pada setengah-maksimum (FWHM) distribusi Gaussian pada panjang gelombang $\lambda$ tertentu sebagai berikut [13].

$$
F W H M_{\lambda}=2.355 \sigma_{\lambda}
$$




\section{Kecerlangan Langit}

Pengukuran kecerlangan langit direkam secara kontinu setiap 30 menit pada pukul 18.00 WIB hingga pukul 05.00 WIB untuk setiap jarak zenith ke segala arah bentangan langit agar dapat dibandingkan kondisi langit yang mengarah ke kota, dengan kondisi langit yang mengarah ke lokasilokasi tertentu. Nilai kecerlangan langit yang akan diukur yaitu nilai kecerlangan langit akibat radiasi dari cahaya lampu kota dengan kecerlangan langit dalam kondisi ideal atau lebih dikenal sebagai "Night Sky Brightness" (NSB). Dengan kata lain, nilai kecerlangan langit mengacu pada cahaya total pada langit malam [14]. Data dari SQM berupa tabulasi data NSB dengan satuan "magnitudo per detik busur kuadrat" atau mag $\operatorname{arcsec}^{-2}$ atau Magnitude per Square Arc Second (MPSAS), magnitudo bintang teredup yang dapat teramati dengan mata telanjang atau lebih dikenal sebagai Naked Eye Limiting Magnitude (NELM). Berikut persamaan yang digunakan oleh Schaefer [15] untuk mendapatkan nilai NELM maupun Bmpsas

$$
\begin{aligned}
& \text { NELM }=7,93-5 \log \left(10^{\left(4,316-\left(\frac{\text { Bmpsas }}{5}\right)\right)}+1\right) \\
& \text { Bmpsas }=21,58-5 \log \left(10^{\left(1,586-\left(\frac{N E L M}{5}\right)\right)}-1\right)
\end{aligned}
$$

temperatur, dan waktu dengan format .csv yang kemudian diolah menggunakan perangkat lunak Python agar dapat dianalisis. Untuk menentukan nilai kecerahan langit pada malam tergelap, cara pertama yaitu diurutkan. Pada kolom MPSAS, data diurutkan dari nilai terbesar hingga nilai terkecil. Nilai terbesar pada kolom ini menunjukkan malam tergelap, sehingga nilai ini digunakan untuk menganalisis lokasi penelitian. Kelebihan dari cara ini yaitu nilai kecerahan langit dapat diketahui secara eksplisit. Cara kedua yang dapat digunakan yaitu dengan mengubah data kecerahan langit menjadi grafik MPSAS terhadap waktu sepanjang malam. Hasil dari pengukuran kemudian akan diklasifikasikan berdasarkan skala Bortle.

\section{Pengukuran karakteristik hujan di sekitar lokasi observatorium}

Karakteristik hujan bulanan dianalisis menggunakan data jangka panjang dengan periode data bervariasi dari 12 hingga 30 tahun, pada empat stasiun terdekat dari wilayah studi, dengan lokasi stasiun observasi klimatologi dapat dilihat pada GAMBAR 2. Informasi terkait lokasi stasiun observasi dapat dilihat pada TABEL 2.

TABEL 2. Lokasi stasiun BMKG.

\begin{tabular}{clcccc}
\hline \multicolumn{1}{c}{ ID } & \multicolumn{1}{c}{ Nama } & Bujur $\left({ }^{\circ}\right)$ & Lintang $\left({ }^{\circ}\right)$ & Elevasi(mdpl) & Periode Data \\
\hline 96291 & Stasiun Iklim Masgar Pesawaran & 105.180 BT & 5.172 LS & 71 & $1996-2010$ \\
96293 & Stasiun Met. Maritim Lampung & 105.330 BT & 5.470 LS & 1 & $1998-2010$ \\
96295 & Stasiun BMKG Klas I Raden Inten II & 105.175 BT & $5.270 \mathrm{LS}$ & 81 & $1981-2010$ \\
96297 & Stasiun Geofisika Kotabumi & 104.870 BT & $4.836 \mathrm{LS}$ & 60 & $1994-2010$ \\
\hline
\end{tabular}




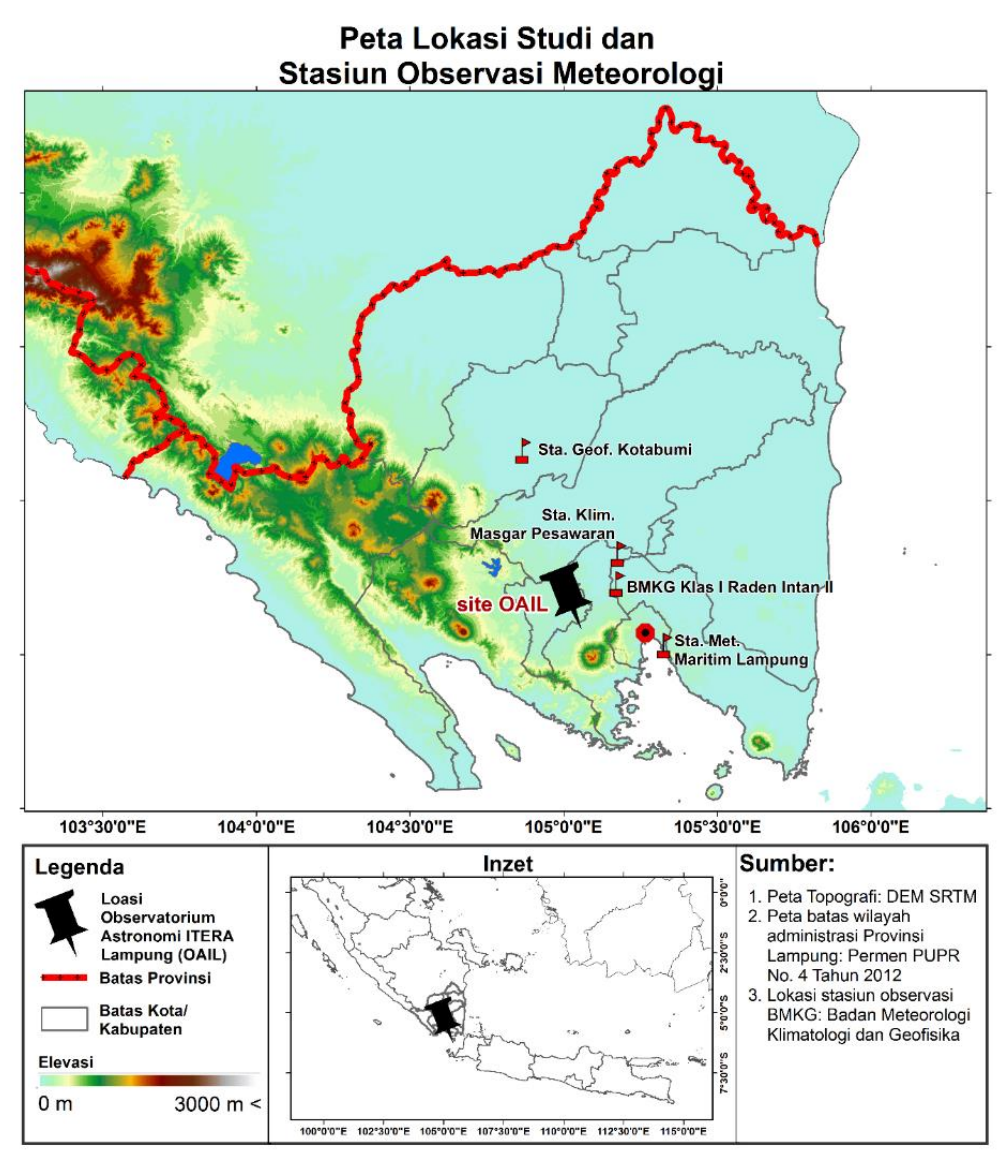

GAMBAR 2. Lokasi survey dan letak stasiun pengamat cuaca BMKG di sekitar wilayah Observatorium.

\section{HASIL DAN PEMBAHASAN}

\section{Ekstingsi Atmosfer}

Peredupan cahaya bintang yang bergantung pada lintasan setelah melewati lapisan atmosfer Bumi atau dikenal sebagai ekstingsi atmosfer [16]. Peredupan cahaya sebagai indikasi adanya proses penyerapan energi. Hasil dari proses pengolahan data merupakan magnitudo bintang setelah melewati atmosfer Bumi atau magnitudo instrumen, sedangkan nilai massa udara ditentukan dengan cara menghitung besarnya jarak zenith objek saat waktu pengamatan. Nilai magnitudo instrumen dan massa udara untuk masing-masing filter BVRI dapat dilihat pada TABEL 3.

TABEL 3. Hasil perhitungan magnitudo instrument dan massa udara.

\begin{tabular}{lccccc}
\hline \multirow{2}{*}{ Parameter } & Filter & \multicolumn{4}{c}{ Objek } \\
\cline { 3 - 6 } & & $\begin{array}{c}\text { Arcturus } \\
\boldsymbol{\alpha} \text { Boo })\end{array}$ & $\begin{array}{c}\text { Cursa } \\
(\boldsymbol{\beta} \text { Eri })\end{array}$ & $\begin{array}{c}\text { Alnath } \\
(\boldsymbol{\beta} \text { Tau })\end{array}$ & $\begin{array}{c}\text { Muphrid } \\
(\boldsymbol{\eta} \text { Boo })\end{array}$ \\
\hline \multirow{3}{*}{ Magnitudo } & $\mathrm{b}$ & $20,13 \pm 0,37$ & $13,48 \pm 0,01$ & $14,75 \pm 0,03$ & $13,51 \pm 0,01$ \\
Instrumen & $\mathrm{v}$ & $20,54 \pm 0,39$ & $11,77 \pm 0,01$ & $13,25 \pm 0,01$ & $13,87 \pm 0,02$ \\
& $\mathrm{R}$ & $18,88 \pm 0,27$ & $14,72 \pm 0,08$ & $13,61 \pm 0,02$ & $14,75 \pm 0,04$ \\
& $\mathrm{I}$ & $19,77 \pm 0,33$ & $15,80 \pm 0,17$ & $14,52 \pm 0,04$ & $14,09 \pm 0,14$ \\
\hline \multirow{3}{*}{ Massa Udara } & $\mathrm{b}$ & 2,62 & 1,44 & 1,78 & 1,85 \\
& $\mathrm{v}$ & 1,95 & 1,48 & 1,81 & 1,59 \\
& $\mathrm{R}$ & 2,45 & 1,47 & 1,80 & 1,77 \\
& $\mathrm{I}$ & 2,54 & 1,46 & 1,79 & 1,83 \\
\hline
\end{tabular}




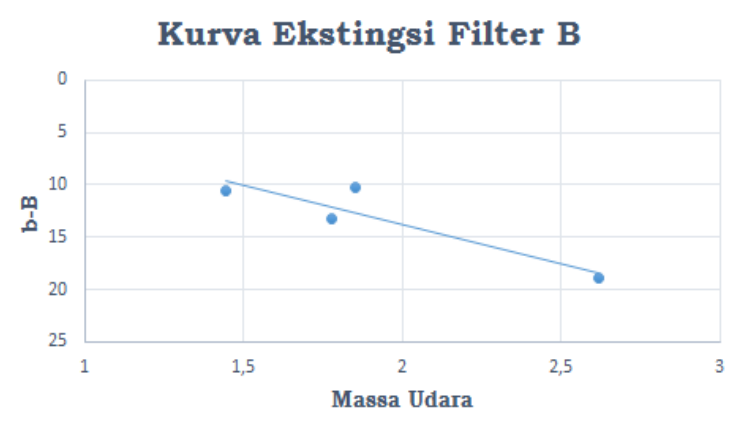

(a)

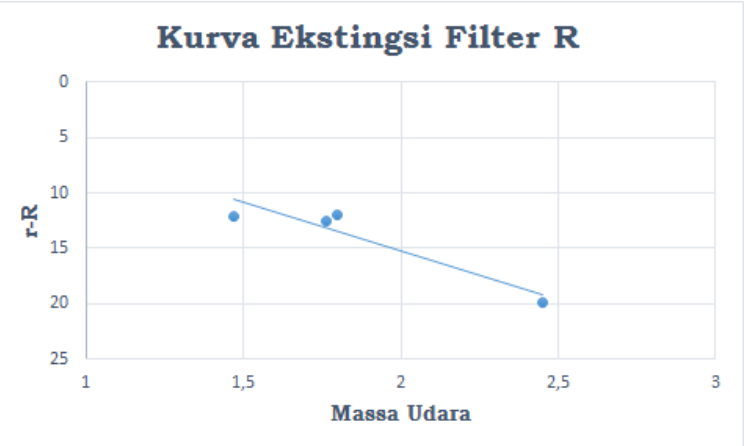

(c)

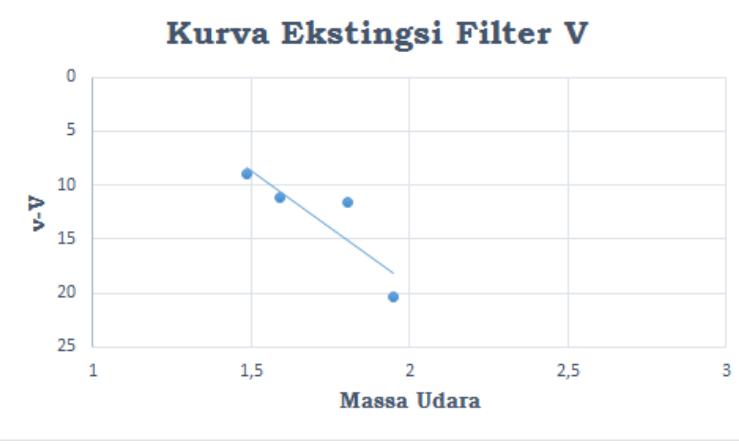

(b)

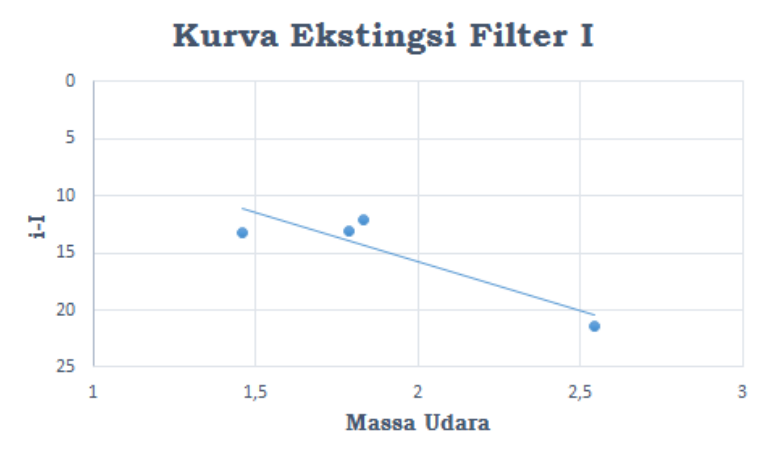

(d)

GAMBAR 3. Kurva hubungan antara massa udara terhadap selisih magnitudo instrumen terhadap magnitudo katalog pada filter BVRI. Hasil fitting linier yang didapat merupakan nilai koefisien ekstingsi pada filter tersebut [8].

Dapat dilihat pada GAMBAR 3, grafik hubungan antara massa udara terhadap selisih dari nilai magnitudo instrumen dengan nilai magnitudo katalog pada filter BVRI. Semakin tinggi massa udara maka magnitudo sebuah bintang akan semakin redup atau nilai magnitudo bintang semakin besar. Nilai massa udara paling kecil adalah satu saat objek yang diamati berada di daerah zenith. Semakin mendekati horizon, maka massa udaranya semakin tinggi sehingga bintang akan terlihat lebih redup akibat lintasan cahaya yang dilalui semakin panjang. Nilai koefisien ekstingsi bergantung pada panjang gelombang atau filter yang digunakan untuk menangkap citra sebuah bintang. Koefisien ekstingsi akan lebih besar pada filter dengan panjang gelombang yang lebih pendek (B) dan nilainya akan menurun untuk panjang gelombang yang lebih panjang (I). Hal ini dikarenakan panjang gelombang yang lebih pendek memiliki energi yang lebih besar sehingga energi pada panjang gelombang yang lebih pendek akan diserap atmosfer lebih banyak dibandingkan pada filter yang memiliki panjang gelombang lebih panjang. Selain itu data keempat bintang diambil pada jarak zenith yang cukup berdekatan sehingga belum dapat merepresentasikan keseluruhan langit. Kondisi cuaca dan lingkungan pada malam pengamatan yang tidak mendukung seperti berawan, kabut, dan angin yang kencang juga mempengaruhi hasil pengamatan [9].

\section{Seeing}

GAMBAR 4.a merupakan citra bintang ganda Albireo, dan Formalhout yang ditunjukan pada GAMBAR 4.d yang telah melalui proses pengolahan data menggunakan perangkat lunak IRAF. Pengukuran seeing sangat sensitif terhadap sifat teleskop itu sendiri seperti ukuran, kualitas optik, stabilitas, dan kualitas drive (Motor Teleskop/Mounting). Dari hasil pengamatan bintang Formalhout dan Albireo diperoleh nilai seeing dan FWHM pada formalhout lebih besar daripada Albireo seperti yang ditunjukan pada TABEL 4. Nilai tersebut juga sangat dipengaruhi oleh kondisi langit saat pengamatan. Saat merekam data citra bintang Formalhout kondisi langit lebih berawan, berkabut dan berangin sehingga turbulensi atmosfer menjadi lebih besar dan berdampak pada hasil parameter seeing [17]. 


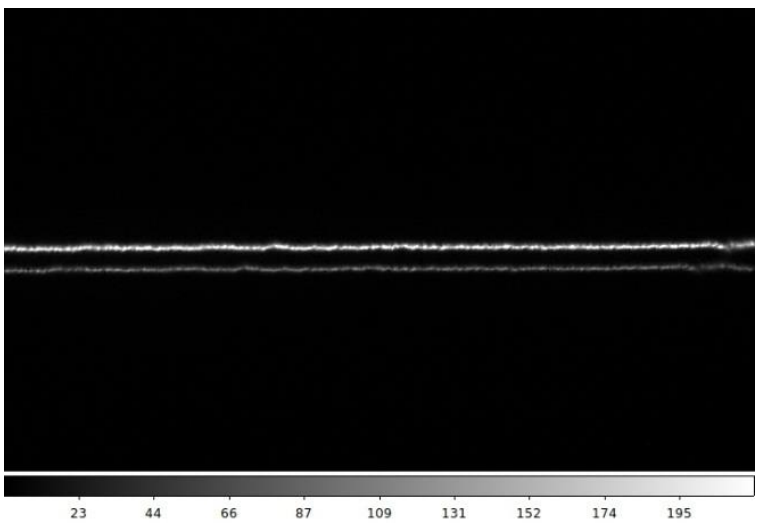

(a)

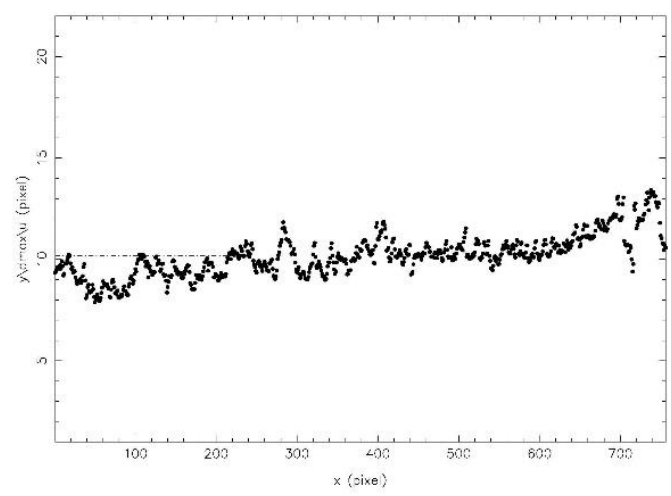

(b)

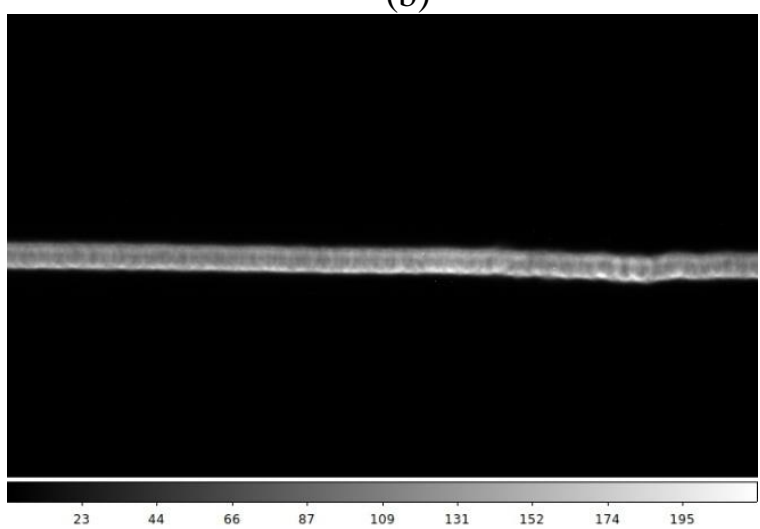

(d)

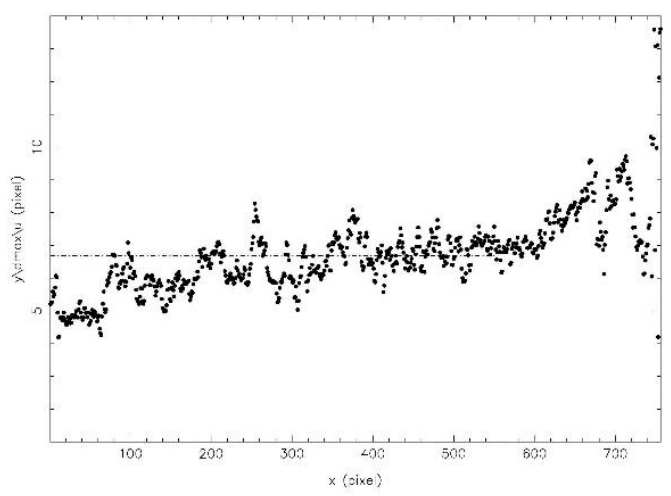

(c)

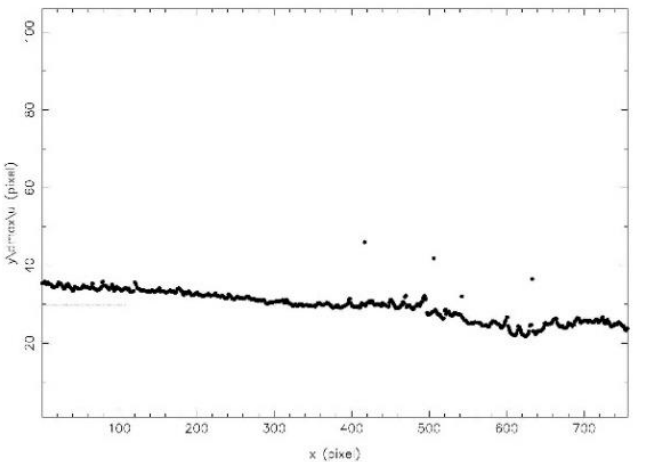

(e)

GAMBAR 4. Hasil pengolahan citra Albireo sebagai bintang ganda (a) dan Formalhout (d), dan hasil diferensial trail bintang relatif terhadap nilai fit polynomial untuk Albireo A (b), Albireo B (c), dan Formalhout (e) (Muztaba, 2017).

TABEL 4. Hasil pengukuran seeing

\begin{tabular}{lccc}
\hline Bintang & Standar Deviaasi & Seeing $(\operatorname{arcsec})$ & FWHM (arcsec) \\
\hline Albireo A & 0,64 & 1,50 & 0,72 \\
Albireo B & 0,79 & 1,85 & 0,89 \\
Fomalhout & 1,49 & 3,5 & 1,68 \\
\hline
\end{tabular}




\section{Kecerlangan Langit}

Hasil pengukuran kecerlangan langit menggunakan SQM pada tanggal 9 dan 10 September 2017 dapat dilihat pada GAMBAR 5. Pengukuran kecerlangan langit di berbagai ketinggian $0^{0}$ sampai dengan $130^{\circ}$ membentang dari arah utara ke selatan pada GAMBAR 5.a dan 5.b nilai kecerlangan langit relatif konstan karena kecilnya gangguan polusi cahaya dari arah selatan yaitu kota Bandar Lampung yang masih terhalang pegunungan, sedangkan dari arah barat ke timur pada GAMBAR 5.c dan 5.d gangguan polusi cahaya lebih dominan di arah timur karena terdapat sumber polusi cahaya yaitu pabrik batu bara yang kemungkinan menggunakan lampu tembak. Dari nilai rata-rata survei kecerlangan langit, berdasarkan skala Bortle, kondisi langit di wilayah observatorium masuk dalam kategori langit transisi urban, dalam artian sedang dalam tahap kota berkembang dengan ciri-ciri masih dapat melihat galaksi bimasakti dengan jelas. Namun perlu adanya regulasi kebijakan mengenai penggunaan lampu dimalam hari, dan daerah bebas lampu kota.

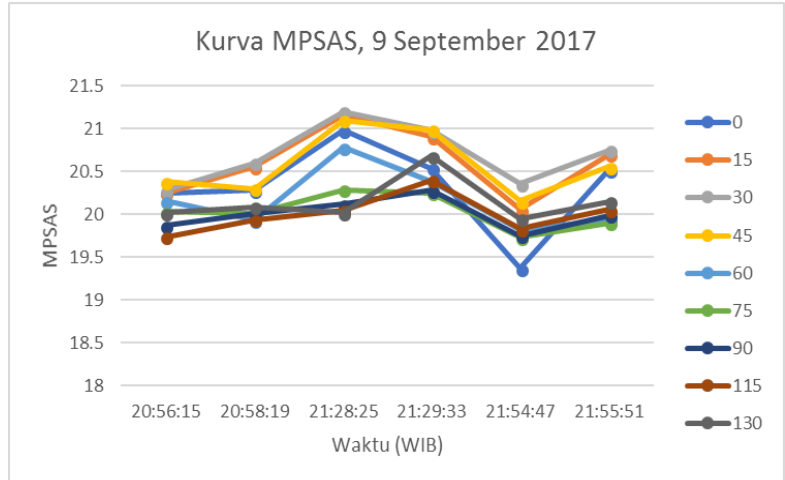

(a)

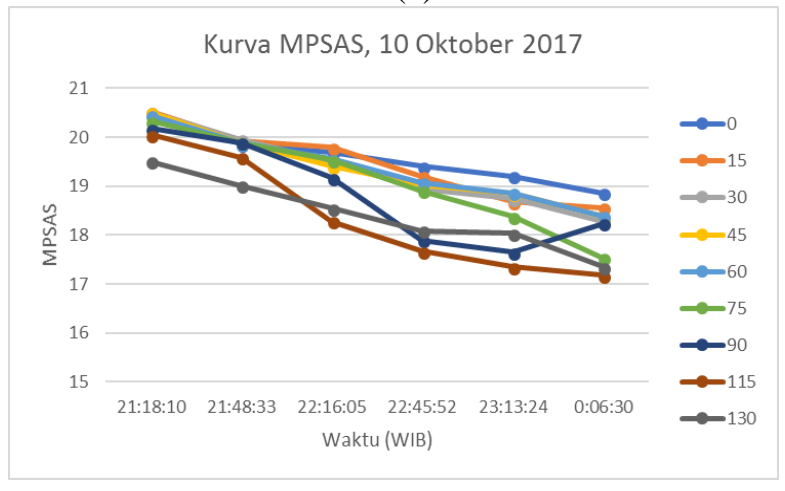

(c)

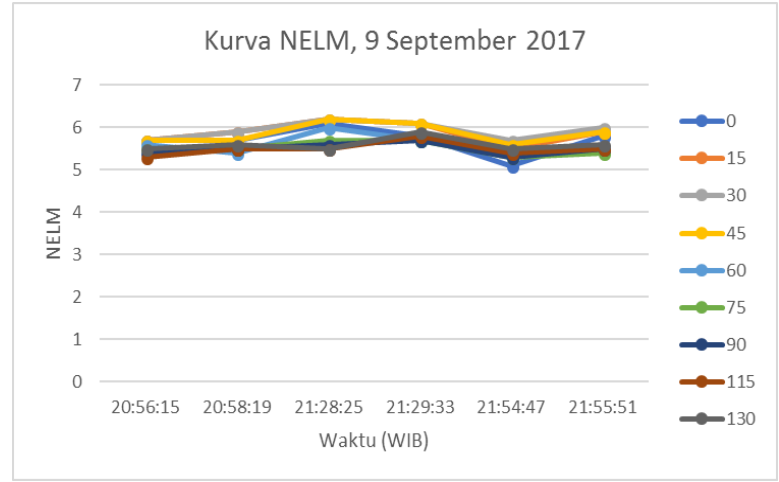

(b)

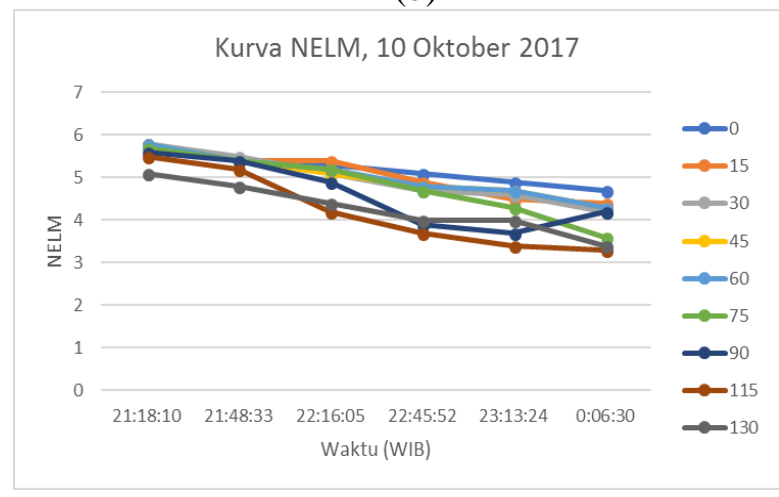

(d)

GAMBAR 5. Hasil pengukuran kecerlangan cahaya menggunakan SQM

\section{Curah Hujan}

Hasil pengukuran meteorologis yang diperoleh dari data 30 tahun pengamatan yaitu sejak 1981 hingga 2010 di stasiun terdekat dari wilayah observatorium berupa grafik hubungan curah hujan ratarata bulanan di sekitar wilayah Lampung yang ditunjukan pada GAMBAR 6. Grafik tersebut menunjukkan bahwa terdapat karakteristik musiman yang mencolok pada keempat data stasiun. Pola curah hujan yang ditandai dengan siklus musiman pengaruh Monsun Asia, dengan curah hujan maksimum terjadi pada November-Maret, dan curah hujan minimum pada Mei-Oktober. Pengaruh Equinox yang terjadi pada bulan Maret dan September setiap tahunnya dapat terlihat dengan adanya peningkatan curah hujan yang siginifikan pada bulan Maret, namun sebaliknya karakteristik ini tidak terlihat jelas pada bulan September. 


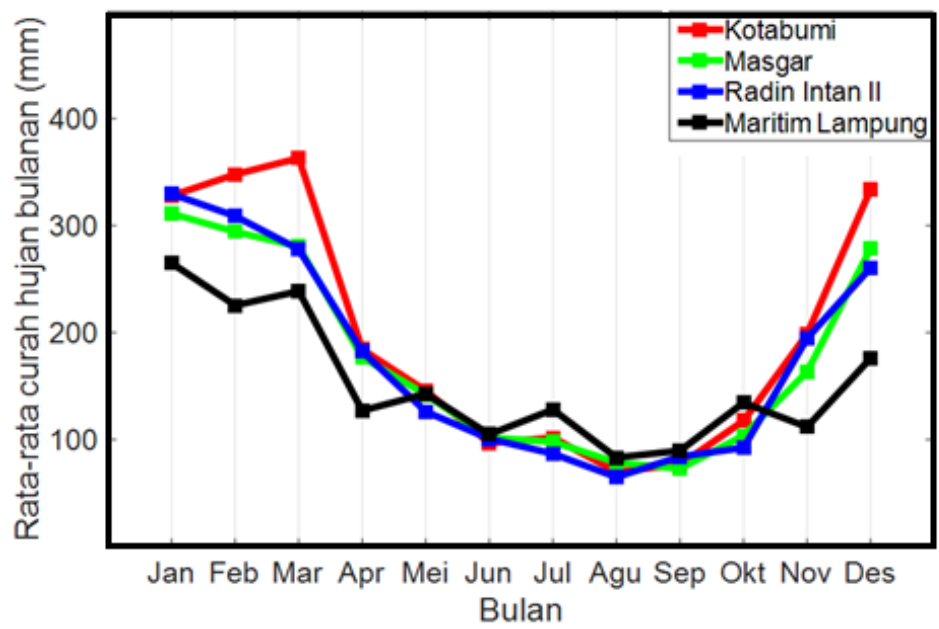

GAMBAR 6. Rata-rata curah hujan bulanan dari 4 stasiun pengamatan BMKG terdekat dari situs pembangunan Observatorium dari hasil 30 tahun pengamatan.

Dengan rata-rata curah hujan minimum pada bulan Mei-Oktober, dan estimasi jumlah hari hujan juga minimum pada bulan-bulan ini, sehingga pengamatan astronomi diharapkan dapat maksimal apabila dilakukan pada bulan Mei hingga Oktober yang memiliki 200 hari cerah. Analisis lebih lanjut menunjukan curah hujan terendah terutama terjadi disekitar bulan Juli-Agustus-September, dimana rata-rata curah hujan bulanan di wilayah studi $<100 \mathrm{~mm}$. Namun adanya pola diurnal di wilayah ini mengakibatkan studi karakteristik awan dan probabilitas hari cerah perlu dilakukan lebih lanjut untuk menghasilkan rekomendasi bulan dan waktu terbaik pengamatan.

\section{SIMPULAN}

Kesimpulan dari hasil survei situs pembangunan observatorium astronomi itera lampung di tahura war, gunung betung sebagai berikut :

1. Jarak zenith antar bintang yang berdekatan masih belum dapat mewakili seluruh daerah langit sehingga masih perlu tambahan pengamatan ekstingsi atmosfer. Namun dari hasil pengamatan sementara nilai magnitudo akan semakin redup apabila nilai massa udara semakin tinggi.

2. Nilai seeing terbaik diperoleh dari hasil pengamatan bintang Albireo A sebesar 1,50 arcsec.

3. Gangguan polusi cahaya lebih dominan dari arah timur di kawasan Teluk Betung. Secara keseluruhan nilai rata-rata survei kecerlangan langit menurut skala Bortle menunjukan bahwa kondisi langit di wilayah observatorium masuk dalam kategori langit transisi urban dengan ciri-ciri masih terlihatnya galaksi bimasakti yang jelas.

4. Jendela pengamatan astronomi pada situs pembangunan observatorium dapat maksimal pada bulan Mei hingga Oktober yang memiliki $~ 200$ hari cerah. Curah hujan terendah terjadi disekitar bulan Juli-Agustus-September, dimana rata-rata curah hujan bulanan di wilayah studi $<100 \mathrm{~mm}$.

Dari hasil survei menunjukan bahwa lokasi Gunung Betung yang menjadi pilihan untuk pembangunan observatorium di Lampung sangat layak untuk dibangun sebuah observatorium.

\section{UCAPAN TERIMAKASIH}

Terimakasih atas program simlitabmas kemenristekdikti dengan nomor 007/SP2H/LT/DRPM/2018, kepada Ir. Mulyadi Irsan M.T. selaku kepala badan LITBANGDA Provinsi Lampung atas kesempatan dan izin yang diberikan untuk melakukan survei di Gunung Betung, dan Komunitas Astronomi Lampung (KALA), yang telah membantu kami selama pengamatan di situs pembangunan Observatorium. 


\section{REFERENSI}

[1] P. Cinzano. (2013, June) Unihedron - Sky Quality Meter. [Online]. HYPERLINK "http://unihedron.com/projects/darksky/sqmreport_v1p4.pdf" http://unihedron.com/projects/darksky/sqmreport_v1p4.pdf

[2] P. Cinzano. (2013, June) Unihedron-Sky Quality Meter L. [Online]. HYPERLINK "http://unihedron.com/projects/sqml/sqmreport2.pdf" http://unihedron.com/projects/sqml/sqmreport2.pdf

[3] P. Cinzano, F. Falchi, and C. D. Elvidge, "The First World Atlas of The Artificial Night Sky Brightness," Monthly Notices of the Royal Astronomical Society, vol. 328, no.3, pp. 689-707, 2001.

[4] E. M. Craine, R. B. Culver, J. C. Craine, and R. A. Tucker, in The Society for Astronomical Sciences 27th Symposium on Telescope Science, Rancho Cucamonga, California, 2008.

[5] M. G. Smith et al., in Preparing for the 2009 International Year of Astronomy: A Hands-On Symposium, San Francisco, 2008.

[6] H. L. Johnson and W. W. Morgan, "On the Color-magnitude Diagram of The Pleiades," Astrophysical Journal, vol. 114, pp. 414-421, 1951.

[7] H. L. Johnson and W. W. Morgan, "Fundamental Stellar Photometry for Standards of Spectral Type on The Revised System of The Yerkes Spectral Atlas," Astrophysical Journal, vol. 117, p. 313, 1953.

[8] H. L. Johnson, "Astronomical Measurements in the Infrared," Annual Review of Astronomy and Astrophysics, vol. 4, p. 193, 1966.

[9] A. N. I. Putri, "Measurement of Atmospheric Extinction Parameter at The Site Development of ITERA Astronomical Observatory, Tahura War, Mount Betung, Lampung," in Seminar Nasional Sains Antariksa, Bandung, 2017.

[10] C. E. Coulman, "The Observation, Calculation, and Possible Forecasting of Astronomical Seeing," Astronomical Society of the Pacific 98, pp. 376-387, 1986.

[11] D. Tody, "The IRAF Data Reduction and Analysis System," in Proc. SPIE Instrumentation in Astronomy VI, 1986, p. 733.

[12] D. Tody, "IRAF in the Nineties," in A.S.P. Conference Ser., 1993, p. 173.

[13] J. Gochermann et al., "Seeing Conditions at Sutherland. Results of the 1992/93 Seeing Campaign," Experimental Astronomy, vol. 9, no. 1, pp. 1-15, 1999.

[14] Johanner Puschnig, Thomas Posch, and Stefan Uttenthaler, "Night Sky Photometry and Spectroscopy Performed at The Vienna University Observatory," Journal of Quantitative Spectroscopy and Radiative Transfer, 2013.

[15] B. E. Schaefer, "Telescopic Limiting Magnitudes," The Astronomical Society of The Pacific, vol. 102, pp. 212-229, 1990.

[16] J. Palmer and A. C. Davenhall, "The CCD Photometric Calibration Cookbook," Council for The Laboratory of The Research Councils, 2001.

[17] Robiatul Muztaba, "Measurement of Seeing Parameter at The Site Development of ITERA Astronomical Observatory," in Seminar Nasional Antariksa, Bandung, 2001. 